\title{
LA LABOR DE LOS PROFESORES NORMALISTAS EN CHILOÉ, CHILE ${ }^{1}$
}

(The work of Normal Teachers in Chiloé, Chile)

Estela Socías Muñoz ${ }^{2}$

\section{RESUMEN}

En Chile se crearon las escuelas normales, formadoras de maestros primarios en 1842 , siendo el argentino Domingo Faustino Sarmiento, su primer Director. Gran importancia tuvieron las escuelas normales de las provincias alejadas de la capital y, especialmente, rurales. En este artículo se persigue analizar la esforzada labor de los profesores normalistas de la Isla de Chiloé, ubicada a 1.000 kilómetros de la capital del país, durante gran parte del siglo XX.

Palabras claves: Profesor Normalista; Isla Grande de Chiloé; Educación Rural.

\begin{abstract}
In Chile were, forming schools for primary teachers in 1842, being the Argentine Domingo Faustino Sarmiento, its first Director. Great importance had the Normal Schools in provinces far from the capital and, especially, rural. This article is intended to analyze the hard work of the normal teachers from the island of Chiloé, located 1,000 km from the capital of the country, for much of the 20th century.
\end{abstract}

Keywords: Normal Teacher; Great Island of Chiloé; Rural education.

\section{1.- Introducción}

Chile está dotado de una diversidad geográfica, climática y cultural sin límites. El norte se caracteriza por la aridez del desierto y el inclemente sol. El sur, en cambio, se construye con lluvias constantes, con atisbos de sol, con bosques nativos y territorios desmembrados por la acción de los hielos. Nosotros nos situaremos en el Archipiélago de Chiloé, localizado entre los paralelos $41^{\circ}$ y $43^{\circ}$ de latitud sur. Comprende principalmente una gran isla, la isla grande de Chiloé, además de un gran número de islas e islotes menores. Este lugar se caracteriza por su paisaje mágico, abundante en mitos y leyendas, y, debido a su geografía, no siempre bien comunicado con el resto del país.

El objetivo fundamental de esta ponencia es reconocer y valorar el trabajo docente normalista entre los años 1900 y 1970, en Chiloé, dentro del contexto educacional nacional y recopilar información que permita conocer la vocación de maestras y maestros durante los años 1930 a 1959, en la ciudad de Calbuco (Frente a la isla de Chiloé).

La metodología de esta investigación se plantea desde una perspectiva históricaeducativa; sin embargo, al abordar una temática reciente se dispondrá de testigos directos 
que suministren valiosa información, que contribuya a la elaboración de un discurso más real. Ello combinado con la metodología de análisis cualitativa, etnográfica y biográfica.

\section{2.- Los Maestros de Chiloé}

Este trabajo está enfocado en aquellos maestros normalistas que desarrollaron su labor profesional en el Extremo Sur de Chile: la Gran Isla de Chiloé y, en especial el archipiélago de Calbuco, lugar con una particular geografía y clima, con una identidad cultural propia, producto del sincretismo desarrollado desde la llegada del conquistador español y el indígena autóctono.

Las historias de estos maestros, sin el reconocimiento merecido, son la principal fuente de inspiración; se desea rescatar su abnegado trabajo con niños y jóvenes del sur de Chile, la entrega de sus conocimientos, de sus valores, de su cariño, dedicación y fe en la educación, apuntando a desarrollar jóvenes que fueran un real aporte a la sociedad en este apartado lugar del mundo, y con una visión mucho más amplia que sus progenitores.

Los profesores normalistas chilotes, que vivían y luego hacían docencia en estos parajes, eran personas con una gran vocación y amor por su tierra; volvían siempre a su lugar de origen para entregar, en su pueblo, lo aprendido en las aulas normalistas (Sarmiento, 1942).

A través del estudio biográfico realizado fue posible conocer de forma directa, fidedigna y en primera persona las vivencias de algunos profesores normalistas chilotes, a la vez que nos permitió comprender su aporte personal en interrelación con la realidad educativa que les correspondió vivir.

Los testimonios de estos maestros y maestras permitieron recuperar sus experiencias enmarcadas en un contexto histórico en el cual ellos fueron partícipes, vinculada con su formación docente, con sus proyectos de vida y su ejercicio profesional. Los materiales autobiográficos constituyen fuentes de información básica y específica, ya que cada persona evoca su experiencia que se mueve entre lo subjetivo y lo objetivo de la situación social e histórica. Estos archivos pasan a formar parte de la memoria colectiva.

Vale la pena recordar que la denominada Escuela Normal nace en Francia, en la ciudad de Reims, en 1785; su fundador fue Juan Bautista de La Salle, y tiene como fuente de inspiración la Ilustración, movimiento intelectual que criticaba las Monarquías Absolutista. Sus representantes Rousseau, Montesquieu, Voltaire, entre otros, promovían la libertad, la igualdad y la educación, como herramientas fundamentales para el hombre. El saber, el conocimiento le otorgaría al hombre la posibilidad de elegir y de disponer de su destino. Por lo tanto, el objetivo de la Escuela era establecer las normas de la enseñanza, de esta forma cada persona o cada niño recibiría una formación similar.

En plena Revolución Francesa la Convención Nacional y el Comité de Instrucción Pública promulgan: "Artículo 1": se establecerá en París una Escuela Normal, donde se requerirían, de todas las partes de la República, de los ciudadanos ya informados en las ciencias útiles, para aprender, bajo los profesores más hábiles en todas las clases el arte de enseñar" (Cox y Gysling, 1990). Para lograr esto se debía hacer una Escuela Modelo, donde los estudiantes de pedagogía pudieran observar la práctica con los niños, es decir, en el mismo establecimiento se encontraba las aulas de los niños y también las aulas de los futuros profesores normalistas. 
Estos docentes chilotes, se formaron en el espíritu y la praxis de las Escuelas Normales de nuestro país, que estuvieron en funcionamiento desde 1842, cuando gobernaba esta República el presidente don Manuel Bulnes, hasta 1974, cuando Chile fue víctima de una dictadura militar. La misión de las Escuelas Normales era formar profesores de enseñanza básica (educación primaria), debido a que antes de este periodo no había formación docente, cualquier persona podía ejercer la docencia sin tener ningún tipo de conocimiento o base moral para educar a los niños. Las necesidades que tuvo este país, al ir evolucionando como República, fue disminuir los niveles de analfabetismo y deserción escolar, ya que existían pocas escuelas y carecían de profesores con formación profesional.

Debido a la formación patriarcal que existía en nuestro país, era impensable que una mujer saliera de su hogar para desarrollar algún oficio o profesión, pero, pese a este panorama social, se funda en 1853, la Escuela Normal de Preceptoras, luego llamada Escuela Normal $\mathrm{N}^{\circ} 1$ de Santiago, donde también las mujeres podían ejercer la docencia; así comienza en nuestro país un proceso de expansión de las Escuelas Normales y por ende la incorporación paulatina de la mujer al trabajo educacional, siendo parte fundamental en la formación de niños y niñas chilenos.

La mística de las escuelas normalistas, consistía en tomar las riendas en la transmisión del conocimiento para sostener y educar al sujeto social, al ciudadano. Sus objetivos se centraban en imprimir unidad y formación técnica o científica a la enseñanza primaria, mediante la creación de la profesión docente.

Con la creación de las Escuelas Normales, se vislumbró fuertemente una apuesta del Estado por la educación, el denominado "Estado Docente", que fue sin duda el impulsor del desarrollo educacional del país y por ende de la pedagogía. Desde 1929 se iniciaba una distinción entre escuelas normales urbanas y rurales, que influyó directamente en la formación de los alumnos y alumnas que recibían en sus aulas. Con las Escuelas normales la educación chilena, en todos sus niveles tuvo un gran auge, existía el concepto de "igualdad de oportunidades", los establecimientos educacionales abrieron sus puertas para que ingresaran por ellas los hijos de los pobres y la naciente clase media. Todo el sistema educacional, hasta el Golpe militar dependía del Ministerio de Educación, por lo que era evidente el compromiso del Estado en ello. Los gobiernos de turno tenía clara conciencia que la educación era la principal herramienta para salir de la pobreza y del subdesarrollo cultural, es decir, la educación era una inversión, no un gasto social.

Pero, esto abruptamente va a cambiar con el Golpe Militar, donde súbitamente se disuelven las Escuelas Normales, la toma del poder por parte de los militares, provocó la transformación en el sistema educacional chileno, se trastocaron los valores por tantos años inculcados, vendiéndose la educación a instituciones privadas, además de traspasar la responsabilidad de la educación pública a las Municipalidades, instituciones que destinaron un mínimo presupuesto para educación. Un decreto eliminó, después de más de un siglo, la experiencia normalista. Molestaba, quizás, el profundo espíritu democrático y laico que caracterizaba a la formación del profesor primario, destinado a tratar en directo con el pobre, el más carenciado. Era el profesor normalista un activo agente social, y ello provocaba sospechas en quienes querían privatizar la educación, dejando para los más pobres una educación de segunda clase. Se eliminó así una tradición, una fuerza que radicaba en el espíritu pedagógico que encarnaba trascendentales personalidades que pasaron por la Escuela Normal, desarrollados al amparo de un Estado efectivamente comprometido con la educación. 
Durante la primera década del siglo $\mathrm{XX}$, se expandió significativamente la formación de profesores primarios con el establecimiento de nueve escuelas normales en diversos puntos del país, además de otras de carácter privado.

Hacia fines de la segunda década del siglo XX, con el asentamiento de un cuerpo profesional docente tanto de egresados Normales como del Instituto Pedagógico se produjo una mayor discusión de orientaciones pedagógicas y la apertura a nuevas influencias extranjeras, se reconoce la importancia de lograr calidad académica y profesional de los profesores.

La mística de las Escuelas Normalistas consistía en tomar las riendas en la transmisión del conocimiento para crear y homogeneizar al sujeto social, al ciudadano. Sus objetivos estaban centrados en:

1. Formar maestros y autorizar el ejercicio de la docencia.

2. Formar un grupo profesional distinto, pero con el mismo rango de otros grupos de profesionales.

3. Imprimir unidad y uniformidad técnica o científica a la enseñanza primaria mediante la creación de la profesión docente.

4. Mediante un refinado criterio de selección, crear profesionales que por sí solos, le otorgaran valor y realce a la profesión de maestro.

Entrando en la tercera década del siglo XX, se produce una etapa de estabilidad para las Escuelas Normales dominado por un asentamiento de lo pedagógico - científico. En lo institucional las seis Escuelas Normales existentes se organizan en 1929 en cuatro urbanas y dos rurales, que a su vez se dividían en hombres y mujeres. En 1933 se estableció la Escuela Normal Superior José Abelardo Núñez, con miras a subir el status de la formación docente mediante la incorporación de actividades de investigación y de formación de formadores. En la década del 40 con el modelo económico de "desarrollo económico hacia adentro", y la importancia dada a la educación por los gobiernos radicales, las escuelas normales aumentaron en número y el nivel de su formación que se equiparó al nivel secundario de educación.

El Instituto Pedagógico de la Universidad de Chile ejerció un liderazgo durante toda la primera mitad del siglo XX, siendo sus profesores muy bien calificados en su conocimiento disciplinario y destacándose un buen número de ellos en el campo de la literatura, la filosofía o la historia. A partir de los años cuarenta surgen otras instituciones de formación docente ligadas al establecimiento de nuevas universidades en varias ciudades del país.

La formación docente de la Universidad de Concepción se independizó curricularmente de la Universidad de Chile y se fundó la Escuela Pedagógica de la Universidad Católica de Chile que en sus primeros años compartió con la Universidad de Chile muchos de sus académicos. Surgieron también Escuelas de Pedagogía y Facultades de Educación en las universidades Austral de Valdivia, Católica de Valparaíso y Católica del Norte.

En 1943 se instaló un Pedagógico independiente del Ministerio de Educación para la formación de profesores de la enseñanza técnico - profesional. En 1952 esta institución 
pasó a formar parte de la recién creada Universidad Técnica del Estado. Todas estas instituciones permitieron ampliar el número de los profesores secundarios lo que era necesario para un sistema educativo que crecía marcadamente.

Los profesores y profesoras normalistas de Chile, especialmente aquellos que desarrollaron su labor en Chiloé, también fueron el resultado del esfuerzo de sus familias y de una comunidad completa. Sus padres, tenían la dura misión de elegir de entre todos sus hijos al más idóneo para esta labor, y la comunidad entera se involucraba, participando padrinos, tíos, abuelos, hermanos y amigos. Este hecho provocaba en el joven -o la jovenun mayor sentimiento de entrega y responsabilidad ya que debían cumplir a cabalidad esta tarea.

Estos jóvenes se vieron enfrentados a una serie de experiencias de vida: como estar lejos de sus hogares, enfrentar su desarrollo social distante de sus comunidades de origen, conociendo otras tradiciones y valores. También debieron sortear difíciles desafíos académicos, pero al superarlos positivamente sabían de sus recompensas. En aquel periodo se requería un número importante de docentes a nivel nacional, debido al fomento de la educación como propuesta del Estado Docente, lo que tuvo un potente desarrollo, sobre todo durante los gobiernos radicales. Sabían que si recibían su título, pronto estarían asignados a una escuela para trabajar, con un sueldo digno y con el prestigio que le otorgaba la misma sociedad por el solo hecho de ser educador. También es importante resaltar en ellos su vocación, en el desarrollo de su carrera, ya que estaban dispuestos a trabajar en el lugar que el Ministerio o Provincial determinara, así también sus familias estaban dispuestas a pagar ese costo de tener a sus hijos ausentes, muchas veces, por largo periodo de tiempo.

Diversos autores del siglo XIX y siglo XX mencionan que la instrucción educacional en Chiloé estaba muy avanzada con respecto al resto del país, en cuanto a que los niveles de analfabetismo eran más bajos. La instrucción primaria, por lo menos, la tenían casi todos los habitantes del archipiélago. En el siglo XIX, muchos jóvenes chilotes buscaban perfeccionarse en una Escuela Normal (generalmente en Santiago), con la intención clara de regresar para difundir una buena educación en sus tierras.

Los jóvenes que lograban llegar hasta Santiago a estudiar pedagogía en las Escuelas Normales era el resultado del esfuerzo de sus familias y de una comunidad completa. Sus padres, tenían la dura misión de elegir de entre todos sus hijos al más idóneo para ésta labor y la comunidad entera se involucraba a través de sus tradiciones y costumbres (las mingas), participando sus padrinos, tíos, abuelos, hermanos y amigos. Este hecho provocaba en el joven o la joven un mayor sentimiento de entrega y de responsabilidad ya que debían cumplir a cabalidad esta tarea.

Santiago fue una de las ciudades que desde el inicio del siglo XX, albergó una mayor cantidad de estudiantes de pedagogía insulares, tenemos que pensar que su adaptación no debe haber sido fácil, desde el viaje, distintas vivencias y formas de ver la vida, la enseñanza recibida y por recibir, las pensiones e internados, estar alejados de la familia por un largo tiempo, además de la carga social de responder bien a las exigencias ya impuestas desde su lugar de origen, debían tener excelentes calificaciones y comportamientos. Esta situación se da en hombres y mujeres, aún cuando en ellas son menos en número, se destaca la profesora de Quellón, Eulogia Bórquez Pérez quién al terminar sus estudios en Castro, una profesora que la estimaba le propuso a su padre enviarla a continuar sus estudios en Santiago, a la Escuela Normal de Preceptoras, siendo tanto el entusiasmo de esta profesora que ella misma viajó en barco de Puerto Montt a 
Valparaíso con Eulogia y dos compañeras más para que estudien en Santiago, internándose en la Escuela. Finaliza sus estudios en diciembre de 1904 y al año siguiente mediante decreto del Ministerio de Educación inicia sus labores en la localidad de Quellón hasta su jubilación.

Un cronista, a fines del siglo XIX decía:

"Castro es una ciudad de pedagogos. Los jóvenes se dedican en su mayor parte al preceptorado, no tienen más ambición que la de estudiar en alguna Escuela Normal del norte. En la conversación familiar se puede notar cual es su preocupación constante en verano, ya sobre que tales jóvenes van a estudiar a la Normal, y que tales otros vienen con sus títulos, y que aquellos o aquellas tendrán que abandonar sus Escuelas por no ser Normalistas, etc". Y luego procedía: "No hay provincia en Chile en la cual está extendida la instrucción primaria en el grado que lo está en Chiloé. Raro, rarísimo es el chilote que no sabe leer y escribir, siquiera medianamente. Desde que Don Manuel Montt tuvo la plausible idea de dar cabida a los hijos de Chiloé en la Escuela Normal de Santiago, y trabajó con decisión por conseguirlo, la instrucción ha tomado un desarrollo extraordinario. Todos los años, veinte o más jóvenes de ambos sexos se presentan a concurso en Ancud para ingresar como alumnos a la Escuela Normal" (S/A, 1896).

Este testimonio reflejaba la importancia asignada a la carrera del profesorado por parte de los jóvenes chilotes ya desde fines del siglo XIX, y la necesidad sentida de contar con una provincia -pobre en esos momentos-, y marginada del aporte gubernamental, pero dispuesta a superar su nivel de educación.

Esta disposición para proseguir estudios de pedagogía de los isleños continuará vigente durante todo el siglo XX, reforzada aún en distintos periodos, que significó a sus jóvenes ser los artífices como maestros del desarrollo educacional en todo el sur del país, los agentes alfabetizadores del austro chileno; incluso muchos de ellos desperdigando sus conocimientos pedagógicos en las provincias de Chile Central, donde se reconoce su valiosa actividad.

Los gobiernos de la década de 1950 comprendieron la importancia del Establecimiento Educacional de Ancud (Quetros, 1953), como formador de alumnas que ejercerían en el mundo rural.

El establecimiento adquirió un fundo donde las estudiantes pudieran practicar labores agrícolas y transmitirla a los futuros alumnos, la orientación agropecuaria constituyó el mayor interés de la escuela, pues las egresadas debían trabajar, en su mayor parte, en escuelas rurales de las zona. Para ello, debían ser capaces de enseñar a sus alumnos el sistema de vida del campesino chilote y con ello nuevos sistemas de cultivos, para así potenciar la calidad de vida del habitante rural.

La profesora normalista Isabel Vidal Miranda, nacida en Castro en 1922, ingresó a la Escuela Normal de Ancud en 1938. Ejerciendo en Chiloé, Llanquihue y Valdivia mencionaba que:

"La Escuela Normal Rural de Ancud cuna de maestros, faro del saber que iluminó el archipiélago, nació pobre, pero que gracias al espíritu y fortaleza de quienes le dieron vida, esta Escuela salió adelante... La 


\begin{abstract}
Directora imprimió un sello personalísimo a esta Escuela en la formación de la auténtica maestra rural, con gran amor al niño campesino, a la tierra y en actividades propias del campo y del futuro labriego, cambiando, además, su mentalidad como lo exigen las inhóspitas regiones del Sur, alejadas de los pueblos y abandonadas a su suerte (...) Poco a poco esta Escuela fue creciendo y con la ayuda de la población ancuditana, fue adquiriendo bibliotecas, piano, violines, servicio médico y dental e imprenta; en la que las alumnas editaban la Revista Mensual "Faro Insular" (Vidal, 2011).
\end{abstract}

Con respecto a las experiencias educacionales, en el caso de las mujeres, ingresaban a la Escuela Normal con 13 o 14 años de edad, siendo solo niñas, tras cumplir sus años de estudio rendían sus pruebas para titularse ante una comisión de profesoras, estricta y severa.

Muy jóvenes salían a ejercer su "apostolado educativo" al sector rural, sin caminos claramente definidos, lejos de la familia y en momentos donde la juventud irrumpía en ellos con todo lo que esto significa. Razón por la que sus vivencias eran mucho más significativas.

Al pasar el tiempo, si no mantenían un contacto más fluido con la urbanidad, paulatinamente, sin notarlo, se iban confundiendo con la cotidianeidad del sector, hasta formar parte integral de la comunidad rural donde vivían y se relacionaban. Muchas veces formaban una familia en los propios lugares de destino.

Los maestros eran personas respetadas y tenían un sueldo permanente, lo que los convertía en sujetos potencialmente atractivos y deseables. Incluso algunas familias incentivaban estas relaciones que generaban prestigio y reconocimiento, de aquí surgía el particular dicho de "marido - maestra" o viceversa. La soledad y la convivencia con sus iguales en aquellos lugares donde el aislamiento reinaba derivaban en estas situaciones.

El Ministerio privilegiaba enviar a los sectores rurales parejas de profesores, y aquellos que trabajaban solos se podían relacionar semanalmente con sus colegas de escuelas cercanas.

De alguna manera incentivaban las relaciones entre colegas, entendiendo que en el sector donde vivían y trabajaban eran guías, líderes, ejemplos comunitarios, encargados de fomentar la sabiduría, la instrucción y la cultura, en aquellos lugares donde los niños y adultos requerían de estos aspectos vitales para ser personas de bien, completamente alfabetizadas. Por ello, se imponía como medida inmediata construir departamentos anexos $\mathrm{y}$, en las mismas Escuelas, habitaciones para el profesor rural, no solo para su convivencia sino para resguardar la salud.

El profesor de Chiloé estaba a merced de todas las dificultades de un medio ambiente complicado y eran pocos los que resistían este tipo de vida y de trabajo en la montaña, en las islas, en las playas, en las aldeas, en el campo, viéndose muchas veces en la necesidad de abandonar sus Escuelas para restablecer su salud quebrantada o sus psiquis afectadas. Sobre el estado físico y moral en que se debatía el maestro de campo, muchas veces sufría la agria crítica de los padres y hasta amonestaciones de jefes poco comprensivos, ya que era enorme la cantidad de licencias solicitadas anualmente. Se hacía necesario estimular al profesor rural facilitándole su traslado a centros urbanos, porque en 
la imposibilidad de hacerlo, había profesores que pasaban toda su juventud y adultez desterrados en Palena, Islas Desertores, Guaitecas, Chauques y otras.

Pese a las dificultades, la prestancia y notoriedad de aquellos maestros y maestras se notaba, generalmente iban vestidos en forma impecable en las ocasiones pertinentes. Ejercían autoridad, y el respeto y estimación hacia ellos era profundo, una mezcla de temor y cariño se reflejaba en los alumnos. Ni soñar contestar mal, alegar o contradecir, no se acostumbraba aquello y era muy mal visto incluso en momentos donde muchos alumnos tenían bastante edad. Nadie dudaba de las opiniones de los maestros ni cuestionaba su trabajo. Lo que decía el maestro era una verdad indiscutida. Incluso tenían cierta licencia para aplicar algunos castigos más simbólicos que físicos, respaldados mayoritariamente por los propios padres que recomendaban o autorizaban al profesor para que procediera como si fueran ellos y así enderezar al chico. Al parecer estas medidas eran efectivas, porque hasta el día de hoy aquellos que se educaron bajo estas reglas comunitarias apoyan la pedagogía y se extrañan del comportamiento estudiantil del presente.

En aquellos años, donde la relación profesor-alumno era otra y, por consiguiente, existía un férreo respeto a los maestros y padres, manteniéndose el orden y el comportamiento social correspondiente.

Eran momentos donde la educación, la moral, las buenas costumbres, el comportamiento, el patriotismo y otros valores de la sociedad chilota se aliaban con la pedagogía. Las reglas de urbanidad y educación cívica se incentivaban. Sabían que la buena educación comienza en el hogar, con valores y principios familiares, y los padres y apoderados consideraban al profesor su guía y mentor.

Así en Chiloé la educación básica estuvo ligada al espíritu normalista desde siempre, esto porque existió una fuerte pedagogía normalista derivada, especialmente, de la antigua Escuela Normal de Ancud.

La educación en la Escuela Normal era gratuita, ya que los gobiernos de la época comprendieron la importancia de impulsar la educación a través de la formación de profesores con vocación y espíritu de servicio, además del riguroso conocimiento que debían tener en todas las disciplinas del saber, de esta manera se estaba invirtiendo en los niños y niñas chilenos para el futuro.

Los profesores normalistas de Chiloé eran de escasos recursos y sus familias hicieron un gran esfuerzo para que pudieran continuar con su educación superior y revertir su situación de pobreza; lo interesante es que todos ellos, luego de educarse, vuelven a sus lugares de origen o zonas aledañas para ejercer la función pedagógica. Muchos de ellos debían sortear una serie de obstáculos para llegar a sus escuelas o para lograr ejercer la docencia en ellas, pero siempre superaron, por ejemplo, las deficiencias de la infraestructura o el poco material didáctico con el que contaban (Uribe, 1986).

Por otro lado, estos profesores no fueron ajenos a las dificultades políticas y sociales que les tocó vivir, la mayoría de ellos manifestó una postura clara, consistente, y una visión bastante crítica de la realidad nacional, elementos tremendamente importantes para un educador, que debe tener una clara visión del mundo en que se desenvuelve.

En una remembranza del profesor Luis Mancilla Pérez respecto a la participación social y el trabajo del maestro decía: 


\begin{abstract}
"Se respetaba al profesor. Nadie cuestionaba su trabajo. Habia estudiado en la Normal, era bombero, futbolista y amigo de nuestros padres en largas y amenas conversaciones en los bares. Eran Alcaldes o regidores, dirigentes de partidos políticos.... Esos profesores de aula, esos que hacen clases y no justificaban su sueldo detrás de un escritorio, publicaban libros, participaban en actividades culturales y organizaciones sociales. Eran respetados por sus vecinos y llegaban a ser autoridades en la ciudad donde vivían..." (Mancilla, 2011).
\end{abstract}

Así, en cada lugar, villa o ciudad de Chiloé, el profesor gozaba de gran respetabilidad y consideración, los vecinos lo reconocían como mentor y consejero, integraba todo tipo de organizaciones en bien de su comunidad, su palabra era siempre oída y respetada, se le contaba de todo, era el confidente. Solucionaba dificultades lugareñas, sermoneaba a los jóvenes y aconsejaba a las jóvenes, ejercía su autoridad en el sector y eran muy pocos los casos en que a esta autoridad pedagógica no la acataban o reconocían. Ellos entendían que la labor del maestro no sólo se limitaba al ámbito escolar, el verdadero maestro se inserta en su medio para servir, dando de sí lo mejor, sin condiciones ni renuncias, porque eran servidores de la vida; en resumen, un patriarca para la comunidad donde vivía y se relacionaba socialmente. Así, los grandes maestros no mueren, continúan viviendo en el pensamiento en la actitud y en el ejemplo de quienes lo formaron.

Prácticamente todos los maestros señalan que se sienten orgullosos de haber optado por la profesión de profesor primario normalista y que no dudarían en volver a ser profesores en la hipotética circunstancia de retornar a esos tiempos hermosos de su juventud. A pesar de una constante queja a la situación miserable de la jubilación, sin comparación con la relevante labor cumplida en su vida laboral.

El régimen militar, en una decisión desafortunada, impuso la lápida a la Escuela Normal con el cierre de ellas entre los años 1973 y 1974, concluyendo con normalismo en Chile, que tanto había aportado al desarrollo educacional del país. Es más, a muchos profesores normalistas les obligaron a jubilar antes de tiempo, para hacer desaparecer una educación donde el lucro era impensable. Con la creación de las Escuela Normales se vislumbró fuertemente una apuesta del Estado por la educación, el denominado estado docente fue sin duda el impulsor del desarrollo educacional del país y por ende de la pedagogía. Desde 1929, se iniciaba una distinción entre normales urbanas y rurales, que influyó directamente en la formación de los alumnos que recibían en sus aulas. En todas se destacaban elementos positivos, como el Internado, alojamiento y alimentación gratis, seis años de estudios post-primarios, alta demanda de ingreso de los mejores alumnos, enseñanza de una pedagogía y metodología igualitaria en todo el país, egresos expeditos en procedimientos técnicos, profesores calificados, infraestructura idónea, entre otros aspectos. Se suma, una rigurosa formación profesional que permitió el éxito de la Escuela Normal.

También es importante destacar la tremenda labor social - popular de la Escuela Normal, respaldada en un momento clave por los gobiernos radicales, al abrir un espacio para que la juventud de Chile pudiera optar a perfeccionarse y obtener un título profesional, con lo que mejoraba sustancialmente su propia calidad de vida y la de su familia. Sin duda, una gran ayuda para las familias de escasos recursos que vieron en esta escuela la exclusiva oportunidad de mejorar socialmente. 
Tenemos la impresión de que muchos casos la opción por la carrera normalista ya estaba asumida por la familia, porque existía un prestigio comunitario para quienes proseguían estos estudios. En este sentido en Chiloé la trilogía familiar más importante era que un hijo sea profesor, otro sacerdote y otro militar; triunvirato perfecto para las tradicionales familias. Además, la familia chilota en ese tiempo era numerosa, y en general las oportunidades laborales no eran las mejores, se vivía casi marginado del desarrollo y progreso de otras provincias, los sueldos exiguos, trabajos esporádicos; por ello, estudiar para profesor o maestro era una posibilidad única considerando que los costos para dicho estudio eran mínimos o no había. Es interesante acotar que muchos alumnos destacados ingresaban a la Normal por consejo e incentivo de los mismos profesores primarios que les hacían clases.

Los maestros normalistas, legendarios en su aporte al desarrollo de la educación, deben ser hoy más que un recuerdo en la historia pedagógica nacional, por ello, sus testimonios son vitales documentos para que en el futuro se aprecie lo trascendente que fueron en el acontecer comunitario y en la enseñanza a generaciones de niños y jóvenes, que gracias a ellos son personas que contribuyen de diversas formas al país.

La Escuela Normal dio base al más magnífico proyecto educacional que haya conocido la República. Un proyecto concebido para producir resultados en décadas posteriores, como así lo hizo, dando brillo a la educación chilena en el contexto de toda Latinoamérica, siendo ella una clave para la consolidación republicana que tanto nos diferenció de otros países, cuyo desorden civil fue la causa de democracias más débiles y economías más vulnerables.

La Escuela Normal constituyó un verdadero cambio para producir el necesario asentamiento en las tareas diseñadas para la educación desde una política de Estado. Por qué no darle la posibilidad real al Estado para que cumpla con su responsabilidad fundamental, cual es la de garantizar una educación con equidad para todos, hoy más que nunca, cuando ya estamos en pleno siglo XXI.

Durante el transcurso del siglo XIX y XX el maestro normalista, independiente de su aporte a la educación chilena, descolló, además, en diversos ámbitos del quehacer nacional, en la política, en la educación superior, en la función pública, en la diplomacia, en el periodismo, en el Parlamento, en el gremialismo, en el sindicalismo; es decir, el profesor normalista ha hecho un aporte difícil de cuantificar, de medir, de sopesar al desarrollo de la sociedad chilena, más allá de su propia vocación educativa. Y todo eso es un valor ético y social que debe perdurar.

\section{3.- Conclusiones}

Se puede concluir esta ponencia, basada en la investigación "La labor de los profesores normalistas en Chiloé, Chile", que estos profesionales de la educación fueron formados con vocación y esfuerzo, lo que hizo que ellos entregaran posteriormente a sus educandos valores, respeto a sus profesores, familias, a la patria y al lugar donde nacieron, dándoles las herramientas necesarias para que pudieran desenvolverse profesionalmente en los distintos medios con sus particularidades y realidades diferentes.

La cercanía, tanto con los alumnos como con su familia, fortalecía la educación personalizada, es decir les entregaba los conocimientos necesarios según las necesidades de cada uno, aplicando el concepto humanista, desarrollando su vocación y educándolos en una misión determinada. Cabe señalar que en el sistema que existía de medio pupilaje e 
internado, le daba la posibilidad a los profesores/ras, entregar una formación completa, ya que el tiempo que debían permanecer en las escuelas era más extenso, desarrollando con fuerza la expresión artística, deportiva y a relacionarse, creando lasos de amistad.

Finalmente, es necesario expresar que la educación de hoy ha tenido significativos avances en lo tecnológico y científico, pero al mismo tiempo está centrada en las competencias y la competitividad, lo que ha producido la deshumanización de la educación $\mathrm{y}$, por ende, de la sociedad. Es indispensable meditar sobre estas últimas reflexiones con el único fin de hacer de la vida, tanto de los educadores como los educandos, más felices y pacíficos, que es el objetivo y el fin último del hombre.

\section{Referencias Bibliográficas}

- Cox, Cristián y Gysling, Jacqueline (1990). La formación del profesorado en Chile (1842-1987). Santiago de Chile, CIDE.

- Mancilla, Luis (2011). Entrevista personal a testigo directo (Profesor Normalista), Ancud.

- Ministerio de Educación Pública (1942). Sarmiento, Director de la Escuela Normal. 1842-1845. Santiago de Chile: Ministerio de Educación Pública.

- Quetros (1953). Revista de la Escuela Normal Rural de Ancud. Año II. N 2, Octubre. Ancud: Imp. La Cruz del Sur.

- S/A (1896). Chiloé. Ancud: Imprenta y Encuadernación “El Austral”.

- Uribe, Luis (1986). Surcos. 1886-1986. Revista Centenario Escuela DN-922. Primer Centenario. Castro: Imprenta Gutty.

- Vidal, Isabel (2011). Entrevista personal a testigo directo (Profesora Normalista), Ancud.

\footnotetext{
1 Este artículo está basado en la Ponencia presentada en el XI Congreso Iberoamericano de Historia de la Educación Latinoamericana, realizado en Toluca, estado de México, México durante el año 2014.

2 Académica de la Universidad Mayor.
}

Recebido: agosto-15 Aprovado: setembro-15 